\title{
Effect of the injection of pure oxygen into a membrane bioreactor on the elimination of bisphenol A
}

\author{
N. Dorival-García $\cdot$ A. Zafra-Gómez $\cdot$ B. Oliver-Rodríguez $\cdot$ \\ A. Navalón · J. González-López · J. L. Vílchez
}

Received: 17 June 2012/Revised: 1 October 2012/ Accepted: 21 December 2012/Published online: 12 February 2013

(C) Islamic Azad University (IAU) 2013

\begin{abstract}
The effect of the injection of pure oxygen instead of air in a membrane bioreactor for the elimination of bisphenol A is investigated. A dynamic experiment was developed in a pilot plant where the aerobic reactor was continuously spiked with $1 \mathrm{mg} \mathrm{L}^{-1}$ of bisphenol A. Air was injected for 10 days and then pure oxygen was injected for another 10 days. The bisphenol A concentration was determined in aqueous phases and activated sludge using simple and sensitive analytical methods based on different extraction procedures and liquid chromatography tandem mass spectrometry analysis. Enzymatic activity was also determined and toxicity tests were performed to discard that the spiked bisphenol A concentration could negatively affect the microorganisms in the bioreactor and, thus, the membrane bioreactor performance. The effluent bisphenol A concentration increased up to $0.26 \mathrm{mg} \mathrm{L}^{-1}$ after 4 days in the air injection treatment, and up to $0.48 \mathrm{mg} \mathrm{L}^{-1}$ after only $12 \mathrm{~h}$ in the oxygen injection treatment. In both cases, this was followed by a decrease in concentration despite the continuous spiking of bisphenol A into the bioreactor. In presence of pure oxygen, bisphenol A concentration reached background levels (below the limit of quantification) after 5 days. In contrast, when using air a total of 10 days were required to reach background levels. The
\end{abstract}

\footnotetext{
N. Dorival-García $\cdot$ A. Zafra-Gómez ( $₫)$.

B. Oliver-Rodríguez · A. Navalón · J. L. Vílchez

Research Group of Analytical Chemistry and Life Sciences,

Department of Analytical Chemistry, Campus of Fuentenueva,

University of Granada, 18071 Granada, Spain

e-mail: azafra@ugr.es

J. González-López

Research Group of Microbiology and Environmental

Technologies, Water Research Institute,

University of Granada, 18071 Granada, Spain
}

injection of pure oxygen instead of air is an important innovation in wastewater treatment, allowing permanent elimination of organic contaminants, avoiding their return to the environment and ensuring the safety of water.

Keywords Bisphenol A - Liquid chromatography tandem mass spectrometry $\cdot$ Membrane bioreactor $\cdot$ Sewage sludge . Wastewater

\section{Introduction}

Endocrine disrupting chemicals (EDCs) are known to mimic natural hormones thus causing adverse effects in humans and wildlife. Their effects lead to reduced fertility, congenital malformations of the reproductive tract and increased incidence of cancer in estrogen-responsive tissues (Bonefeld-Jørgensen et al. 2007). Recent studies focus on anthropogenic EDCs, such as synthetic hormones, a great variety of pharmaceuticals and personal care products, as well as a large amount of industrial chemicals, especially BPA, PCBs, dioxins, pesticides, phthalates, alkylphenols and alkylphenol ethoxylates (Smith 2009).

BPA is the EDC causing the greatest concern in the scientific and medical community, because its effects are even more pernicious than those caused by other EDCs. BPA can interact with estrogen receptors and is a human androgen receptor antagonist, even at low doses. It is thought that BPA can negatively affect the neuroendocrine, behavioural and cognitive functions of individuals (Takayanagi et al. 2006). In addition, BPA may also cause feminization of numerous species, inhibition of male phenotype and spermatogenesis, stimulate the growth of breast tumour cells, act as teratogenic and carcinogenic agent, and can affect the thyroid function (Furuya et al. 2006; Stowell et al. 2006). The presence of 
BPA in blood is also associated with recurrent miscarriage and development of polycystic ovary syndrome (Meeker et al. 2009).

BPA is one of the most produced chemicals in the world, with an annual production of more than 3.2 million tons (EPA 2005). It is used in the manufacture of polycarbonate plastics and epoxy resins used to line metal cans, and in many plastic products including baby bottles, toys, water pipes, drinking and food containers and other food-contact items, eyeglass lenses, dental monomers (composites and sealants) and medical equipments. The migration from food and beverage containers is considered as the primary route of human exposure to BPA. As a consequence, it can be found in biological fluids and tissues (Vandenberg et al. 2007). Environmental exposure to BPA is also a cause of concern. Wastewater containing BPA is a source of contamination of the aquatic environment (Kang et al. 2006), and low concentrations of BPA are able to cause effects if the exposure is continuous. BPA is not completely removed by currently available wastewater treatments, consequently it remains in effluents, at concentrations ranging from very low levels - ng $\mathrm{L}^{-1}$ (Drewes et al. 2005; Lagana et al. 2004) — to high levels-mg L ${ }^{-1}$ (Clara et al. 2005; Vethaak et al. 2005)_including extremely high levels in WWTP effluents from factories$\mathrm{mg} \mathrm{L}^{-1}$ (Mohapatra et al. 2010). The discharge from such effluents is the main responsible for the wide distribution and occurrence of BPA in surface waters, from $0.5 \mathrm{ng} \mathrm{L}-1$ (Kuch and Ballschmiter 2001) to $1 \mathrm{mg} \mathrm{L}^{-1}$ (Vethaak et al. 2005); ground waters, up to $0.93 \mathrm{mg} \mathrm{L}^{-1}$ (Hohenblum et al. 2004); and even in drinking waters, up to $5 \mathrm{ng} \mathrm{\textrm {L } ^ { - 1 }}$ (Rodríguez-Mozaz et al. 2004). Incomplete removal of BPA by existing WWTPs is the result not only of the fluctuation of BPA levels in the influent, but also of the processes that take place at the WWTPs, and as well as the operational conditions.

Effluents containing BPA after landfill leachate treatment are known to be a source of BPA contamination in the aquatic environment; from groundwater enters rivers, streams and drinking waters (Nascimento Filho 2003). Evidence exits demonstrating that BPA poses a serious threat to aquatic life even at the low concentrations at which it is found in aquatic ecosystems (Talsness et al. 2009).

As the conventional activated sludge process is not capable of removing all the BPA, new treatments need to be considered to minimize the discharge of this compound. Membrane bioreactors (MBR) are a satisfactory alternative providing significant improvements over conventional treatments, like separation of treated waters by membrane filtration, which ensures the absence of solid particles and microorganisms in the effluents. MBRs are operated at higher biomass concentration, which means that the plant can operate at longer solids retention time (SRT) facilitating additional biological transformation of micropollutants in general. While some studies exist on the fate of BPA in MBRs (Hu et al. 2007; Chen et al. 2008), there is little information about the final fate of the compound in WWTPs. Elimination of BPA from waters do not ensure its ultimate degradation because the hydrophobic properties of BPA facilitate its adsorption on the sludge and on the ultrafiltration membrane during wastewater treatment, and complete degradation is not achieved under these conditions (Spring et al. 2007). More research is required regarding the water/sludge partition ratio of BPA to develop processes that help to minimize sorption of the compound on sludge (Ivashechkin et al. 2004).

Other problem related to BPA is the generation of byproducts during depuration process and improving the efficiency of the treatments has become, therefore, strictly necessary. In this respect, several studies have focused on the application of tertiary treatments, which usually include an oxidative process. These treatments are usually effective (Lenz et al. 2004; Schröder 2006) but they may result in high expenses and secondary pollution, caused by the presence of residual amounts of the oxidants or their byproducts in water.

The aim of this work is to study the final fate and the main elimination pathways of BPA using the MBR technology. In addition, the work proposes an alternative to use pure oxygen instead of air to increase significantly the driving force for oxygen mass transfer for aeration and provide more oxidative conditions into the bioreactor, enhancing the degradation processes. Although aeration represents the major power input in a MBR system (about $90 \%$ of biological treatment), this alternative becomes feasible because the use of pure oxygen can lead to a reduction in the operating costs of about $20 \%$ in comparison with air, resulting in an oxygen positive balance, because the required energy for processes is much lower (15-20\%). In order to fulfill this objective, we carried out a dynamic experiment in a MBR pilot plant. The BPA removal efficiency was evaluated and compared in two different situations: air injection and pure oxygen injection into the bioreactor. The enzymatic activity was also tested during the whole experiment to determine the effect of air and pure oxygen on the microbiological activity in the bioreactor.

\section{Materials and methods}

\section{Chemicals}

Analytical grade standards of bisphenol A (BPA) and deuterated BPA $\left(B P A-d_{16}\right)$, the substrates for testing 
enzymatic activity and nutrient broth for toxicity tests, were purchased from Sigma-Aldrich (St. Louis, MO, USA). Chlorinated derivatives of bisphenol A (Cl-BPA, $\mathrm{Cl}_{2}$-BPA, $\mathrm{Cl}_{3}$-BPA, $\mathrm{Cl}_{4}$-BPA) were synthesized in our laboratory (Vílchez et al. 2005). Stock solutions of BPA and derivatives were prepared in methanol, stored at $-20{ }^{\circ} \mathrm{C}$ and prepared fresh monthly. Working standard mixtures were prepared by diluting the individual stock solution in methanol or in the initial mobile phase immediately before use. They were stored at $4{ }^{\circ} \mathrm{C}$ in dark glass bottles and prepared fresh weekly. The aqueous solutions of substrates for testing enzymatic activity, and the corresponding buffer solutions were prepared at the established concentrations, stored at $4{ }^{\circ} \mathrm{C}$ and prepared fresh weekly. LC-MS grade methanol and water-used for preparation of standards, acetone, ethyl acetate and ammonia ( $>25 \%)$ were purchased from Fluka (St. Louis, MO, USA). Substrates and reagents for enzymatic activity and toxicity tests, as well as the salts for the culture media were obtained from Panreac (Barcelona, Spain). Water $(18.2 \mathrm{M} \Omega \mathrm{cm})$ was purified using a Milli-Q system from Millipore (Bedford, MA, USA). Solid-phase extraction (SPE) sorbents were silica-based bonded C18 cartridges LiChrolut RP-18 (500 mg, 3 mL) from Merck (Darmstadt, Germany). Wastewater samples were filtered through a $0.45 \mu \mathrm{m}$ cellulose acetate disk filter (Millipore) before analysis.

\section{Instrumentation and software}

Extraction procedures of sludge were performed in a Milestone (ETHOS SEL) microwave solvent extraction Labstation (Sheldon, CT, USA), operating at $2,455 \mathrm{MHz}$ with a maximum delivered power of $1,000 \mathrm{~W}$. The time, temperature and microwave power control were adjusted and controlled throughout the process using the easyWAVE 3 software, version 3.2.1.0. Detection and quantification of the analytes were performed using an Agilent 1200 series (Agilent Technologies Inc., Palo Alto, CA, USA) liquid chromatograph (LC) coupled "on line" to an API 2000 (Applied Biosystems, Foster City, CA, USA) triple quadrupole mass spectrometer using an atmospheric pressure chemical ionization (APCI) interface. A Gemini $\mathrm{C}_{18}$ column $(100 \times 2.0 \mathrm{~mm}$ i.d., $3 \mu \mathrm{m}$ particle size $)$ and a $\mathrm{C}_{18}$ guard column, both supplied by Phenomenex (Torrance, CA, USA) were used. For pH measurements, a Crison 2000 digital $\mathrm{pH}$-meter with a combined glass- $\mathrm{Ag} / \mathrm{AgCl}(\mathrm{KCl}$ $3 \mathrm{M}$ ) electrode (Crison Instruments S.A, Barcelona, Spain) was used. A vortex-mixer (Yellow line, Wilmington, NC, USA); a Hettich Universal 32 centrifuge (Tuttlingen, Germany), and a Memmert oven (Schwabach, Germany) were also used. Sludge used for blank assays of enzymatic activity was autoclaved in a RAYPA autoclave (Barcelona,
Spain) and samples were incubated in a Memmert incubator (Schwabach, Germany). Absorbance of supernatants for enzymatic activity and toxicity tests was measured in an UNICAM 5625 UV/Vis spectrophotometer (ATI UNICAM, Brackley, UK). SPE was carried out in a Supelco (Madrid, Spain) vacuum manifold for 12 columns connected to a Supelco vacuum tank and to a vacuum pump. Data were analyzed by either one-way or multi-factor analysis of variance (ANOVA), using the software package Statgraphics 5.0 (STSC, Rockville, MD, USA) (Statgraphics 1982-2009) to identify significant differences between measurements. A level of $95 \%(P<0.05)$ was considered statistically significant.

Membrane bioreactor pilot plant description and operational conditions

The MBR pilot plant used in the experiments (Fig. 1) was provided by Air Liquide España from Zenon S.A. The MBR pilot plant has a sidestream configuration and consisted of a cylindrical bioreactor with an operational volume of $385 \mathrm{~L}$ into which air or pure oxygen is applied; and a rectangular bioreactor of $89 \mathrm{~L}$, where two polyvinylidene difluoride (PVDF) hollow fibre membrane modules (Zenon ${ }^{\circledR}$ ), with an effective area of $1.86 \mathrm{~m}^{2}$ and a nominal pore size of $0.04 \mu \mathrm{m}\left(\mathrm{ZW}-10 \mathrm{Zenon}^{\circledR}\right)$ were installed. Control devices to monitor membrane pressure, temperature of the activated sludge, suspension solids and dissolved oxygen (DO) were also available. The MBR was operated using urban wastewater from the primary settling tank of the wastewater treatment plant (WWTP) located in the city of Granada (Spain). Table 1 summarizes the operational conditions of the pilot plant for the experiments.

The characteristics of wastewater were analyzed daily during the whole experiment. The average values for each parameter used to feed the bioreactor were: $330 \mathrm{mg} \mathrm{L}^{-1}$ total chemical oxygen demand (COD), $360 \mathrm{mg} \mathrm{L}^{-1}$ biochemical oxygen demand at 5 days $\left(\mathrm{BOD}_{5}\right), 80 \mathrm{mg}$ total $\mathrm{N}$ $\mathrm{L}^{-1}$. Removal was around $90 \%$ for total $\mathrm{COD}$ and for nitrogen, when pure oxygen was used as source of aerobic conditions in the bioreactor. The elimination performance was $97 \%$ for suspended solids. The bioreactor was started up with no previous inoculation; thus, the microorganisms in the sludge came from the influent wastewater. Air or pure oxygen was applied into the cylindrical bioreactor to provide suitable aerobic conditions for the biological processes that will take place. DO was within the range of $2-4 \mathrm{mg} \mathrm{L}^{-1}$. In the rectangular bioreactor, aeration was applied to create turbulence and delaying membrane fouling. The biomembrane process uses a vacuum system to pull the wastewater through the membrane that is then stored in a third tank $(25 \mathrm{~L})$. The flow is reversed regularly for turbulence 


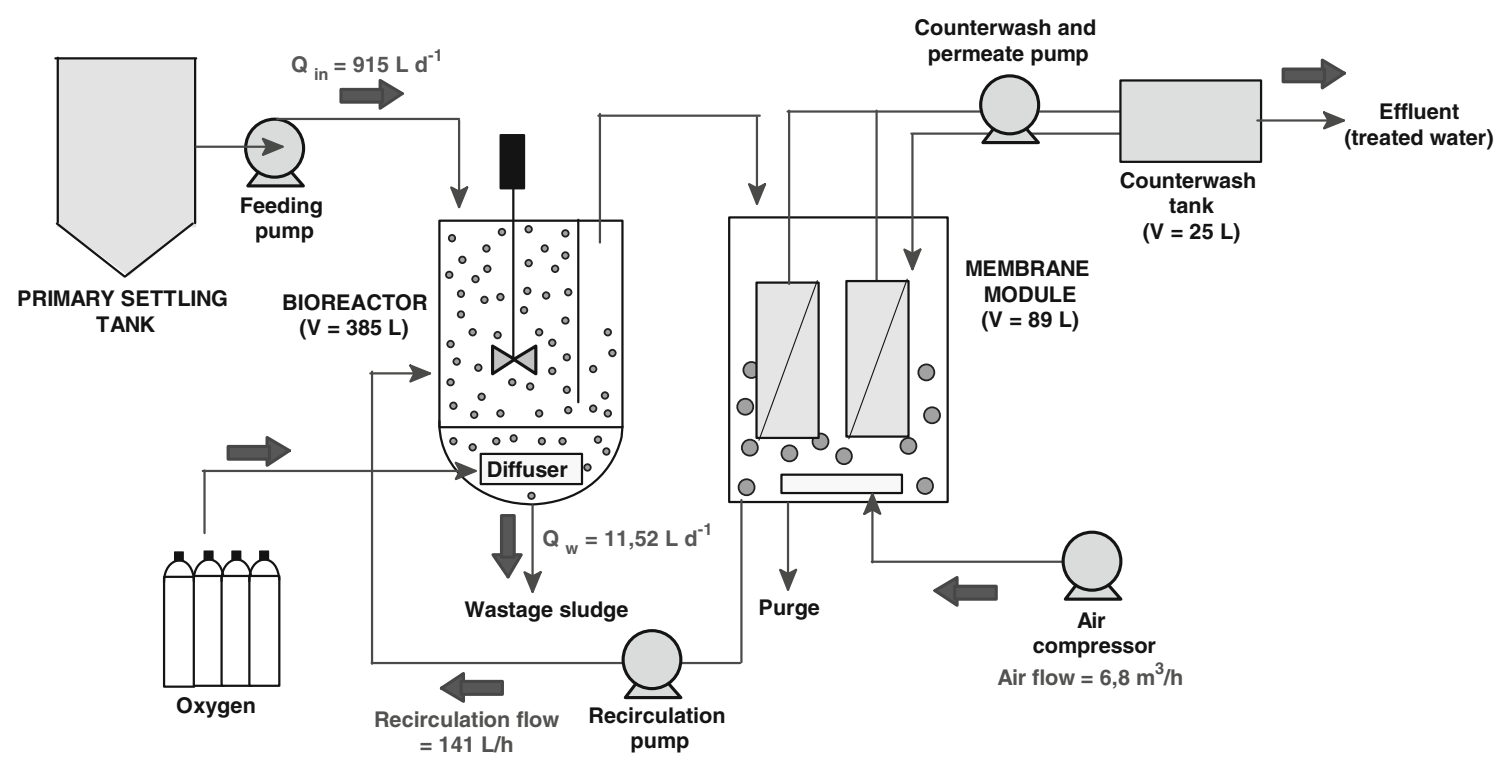

Fig. 1 Schematic diagram and picture of the MBR pilot plant including dimensions and typical flow rates

Table 1 Operational and physicochemical parameters of the MBR pilot plant during the experiments a It was reported the mean value for each 10 days examination period

\begin{tabular}{|c|c|c|}
\hline Parameter & Influent & Effluent \\
\hline \multicolumn{3}{|c|}{ Physicochemical parameters of influent and effluent water of the MBR pilot plant ${ }^{\mathrm{a}}$} \\
\hline $\mathrm{pH}$ & 7.6 & 7.5 \\
\hline Conductivity $\left(\mu \mathrm{S} \mathrm{cm}^{-1}\right)$ & 1,419 & 1,016 \\
\hline $\operatorname{COD}\left(\mathrm{mg} \mathrm{L}^{-1}\right)$ & 330.0 & 30.6 \\
\hline $\mathrm{BOD}_{5}\left(\mathrm{mg} \mathrm{L}^{-1}\right)$ & 359.8 & 26.4 \\
\hline $\operatorname{MLSS}\left(\mathrm{mg} \mathrm{L}^{-1}\right)$ & 120.3 & 2.8 \\
\hline Total nitrogen $\left(\mathrm{mg} \mathrm{L}^{-1}\right)$ & 80.0 & 7.6 \\
\hline $\operatorname{MLVSS}\left(\mathrm{mg} \mathrm{L}^{-1}\right)$ & 105.0 & 2.5 \\
\hline Parameter & Unit & Value \\
\hline \multicolumn{3}{|c|}{ Operational conditions of the MBR pilot plant } \\
\hline Influent flow rate & $Q_{\text {in }}\left(\mathrm{L} \mathrm{day}^{-1}\right)$ & 915.6 \\
\hline Wastage sludge flow rate & $Q_{\mathrm{w}}\left(\mathrm{L}\right.$ day $\left.^{-1}\right)$ & 11.52 \\
\hline Hydraulic retention time & HRT (day) & 0.5 \\
\hline Sludge retention time & SRT (day) & 32 \\
\hline Aeration (oxygen flow) & $\mathrm{g} \mathrm{h}^{-1}$ & 500 \\
\hline Membrane module aeration & $\mathrm{m}^{3} \mathrm{~h}^{-1}$ & 6.8 \\
\hline \multirow[t]{2}{*}{ Recirculation flow } & $\mathrm{L} \mathrm{h}^{-1}$ & 141 \\
\hline & Experiment 1 (with air) & Experiment 2 (with pure oxygen) \\
\hline \multicolumn{3}{|c|}{ Physicochemical parametersof the bioreactor for each experimental period ${ }^{\mathrm{a}}$} \\
\hline $\mathrm{pH}$ & 7.02 & 6.98 \\
\hline Temperature $\left({ }^{\circ} \mathrm{C}\right)$ & 23.8 & 27.3 \\
\hline $\operatorname{MLSS}\left(\mathrm{mg} \mathrm{L}^{-1}\right)$ & 9,300 & 8,500 \\
\hline $\operatorname{MLVSS}\left(\mathrm{mg} \mathrm{L}^{-1}\right)$ & 8,000 & 7,500 \\
\hline Conductivity $\left(\mu \mathrm{S} \mathrm{cm}^{-1}\right)$ & 1,156 & 1,063 \\
\hline Dissolved oxygen $\left(\mathrm{mg} \mathrm{L}^{-1}\right)$ & 2.09 & 3.06 \\
\hline Oxidation-reduction potential $(\mathrm{mV})$ & +155.6 & +227.3 \\
\hline
\end{tabular}


promotion, which allows passing treated water through the membrane in the reverse direction. This contributes to the cleaning of the membrane surface and avoids increase in transmembrane pressure (TMP) value, which is an indicator of the degree of membrane fouling. Plant operation consisted of 10-min cycles: a filtration cycle lasting $9 \mathrm{~min} 45 \mathrm{~s}$ followed by a back flush cycle lasting $15 \mathrm{~s}$. A system for the purge of excess sludge was also provided.

\section{Experimental protocol}

The bioreactor was continuously spiked with $893 \mathrm{mg}$ of BPA per day, equivalent to a total influent BPA concentration of $1 \mathrm{mg} \mathrm{L}^{-1}$. This concentration was selected based on a previous study (Lindblom et al. 2009) to evaluate the MBR capability for BPA removal from waters under conditions of high pollution levels of this contaminant. In order to establish differences between the use of air and pure oxygen to provide aerobic conditions in the bioreactor, two experiments were performed during spring 2010 , with a mean temperature inside the bioreactor of $26^{\circ} \mathrm{C}$. The experimental work in the plant was divided in two consecutive stages: the first experiment was performed during 10 days and involved the use of air from a compressor as source of oxygen for the bioreactor. Once the first experiment was completed, the second one was immediately initiated, involving the use of pure oxygen during other 10 days. The mean values for the physicochemical parameters measured in the bioreactor during the two 10-day experiments are presented in Table 1. During both experiments, samples of influent, effluent water and sewage sludge were collected at defined time intervals to determine BPA concentration. Samples from the bioreactor mixed liquor were also taken for the analysis of the enzymatic activity of the bacterial populations living in the bioreactor. Before the spiking of the bioreactor with BPA, samples of the bioreactor mixed liquor were taken for the corresponding toxicity tests.

Sample collection and analysis

\section{Sampling and extraction of samples for EDCs determination}

All water and sewage sludge samples were collected and stored in amber glass bottles. Immediately after the sampling, decreased biological activity was achieved by addition of $1 \%(\mathrm{v} / \mathrm{v})$ aqueous formaldehyde. Once in the laboratory, water samples were centrifuged, filtered and stored in the dark at $4{ }^{\circ} \mathrm{C}$, until analysis. Sludge samples were also centrifuged and the solid fraction was recovered, dried in a heater at $60{ }^{\circ} \mathrm{C}$ to constant weight and finely ground $(\leq 1.41 \mathrm{~mm})$. The samples were kept in the dark at $4{ }^{\circ} \mathrm{C}$ until analysis. Both types of samples were processed within the allowable holding period. The determination of BPA concentration in water samples was performed according to a method described elsewhere (Zafra-Gómez et al. 2008) with some modifications. Briefly, BPA was extracted from samples using a SPE procedure with LiChrolut RP-18 cartridges. $100 \mathrm{~mL}$ of wastewater was passed through the cartridges and after extraction; the analytes were eluted with a mixture of diethyl ethermethanol $(90: 10 ; \mathrm{v} / \mathrm{v})$. Eluents were evaporated to dryness at $50{ }^{\circ} \mathrm{C}$ under a stream of nitrogen. The residues were redissolved in $500 \mu \mathrm{L}$ of the initial mobile phase and directly injected into the LC system. The determination of sorbed BPA in sludge samples was performed using a modified analytical method that was adapted for sludge samples (Liu et al. 2004). Briefly, Sludge sample (1.0 g) was placed in a microwave Teflon vessel with $10 \mathrm{~mL}$ of ethyl acetate as extraction solvent. The suspensions were extracted for $10 \mathrm{~min}$ (10 min for holding) at $90{ }^{\circ} \mathrm{C}$ and at $1,000 \mathrm{~W}$. After microwave irradiation, the vessels were allowed to air-cool inside the microwave to below $45{ }^{\circ} \mathrm{C}$. The extract was centrifuged for $35 \mathrm{~min}$ at $3,634 \times g$ and evaporated to dryness at $50{ }^{\circ} \mathrm{C}$ under a stream of nitrogen. The residue was resuspended with $500 \mu \mathrm{L}$ of the initial mobile phase, centrifuged at $3,634 \times g$ for $10 \mathrm{~min}$ and the supernatant was directly injected into the LC system. To study the efficiency of the extraction procedures, a recovery assay was carried out. Water and sludge samples were spiked in triplicate with a standard solution of compounds $\left(1 \mu \mathrm{g} \mathrm{L} \mathrm{L}^{-1}\right.$ for wastewater and $200 \mu \mathrm{g} \mathrm{kg}^{-1}$ for sludge samples). Spiked samples and a blank sample were analyzed and the recoveries of the analytes were above 96 and $94 \%$ on average for wastewater and sludge, respectively. The limit of quantification (LOQ) of the method was calculated on the basis of a signal-to-noise ratio $(\mathrm{S} / \mathrm{N})$ of 10 . For BPA, the LOQ was $52 \mathrm{ng} \mathrm{L}^{-1}$ in wastewater and $18 \mu \mathrm{g} \mathrm{kg}^{-1}$ in sludge. For the derivatives, the LOQ was between 24-43 $\mathrm{ng} \mathrm{L}^{-1}$ for wastewater and $20-30 \mu \mathrm{g} \mathrm{kg}^{-1}$ for sludge.

\section{LC-MS/MS analysis}

A Gemini $\mathrm{C}_{18}$ column $(100 \times 2.0 \mathrm{~mm}$ i.d., $3 \mu \mathrm{m}$ particle size) and a $\mathrm{C}_{18}$ guard column were used for LC analysis. The flow rate was $350 \mu \mathrm{L} \mathrm{min}{ }^{-1}$, the column was maintained at $40{ }^{\circ} \mathrm{C}$, and the injection volume was $40 \mu \mathrm{L}$. The standards and samples were separated using a mobile phase consisting of $0.025 \%(\mathrm{v} / \mathrm{v})$ ammoniacal aqueous solution and $0.025 \%(\mathrm{v} / \mathrm{v})$ ammonia in methanol, with a methanol gradient from 60 to $100 \%$ in 5 min. Multiple reaction monitoring (MRM) was used. APCI was performed in the negative ion mode. The mass spectrometric conditions 
were as follows: ion source temperature, $350{ }^{\circ} \mathrm{C}$; IonSpray voltage, $-3 \mathrm{kV}$, nitrogen was used as both the curtain gas at $30 \mathrm{psi}$ and ion source gas 1 and 2 at 50 and $30 \mathrm{psi}$, respectively; collision gas was air at $10 \mathrm{psi}$. To optimize MRM conditions, a full scan and a product ion spectrum for each compound were first acquired by infusion of standard solutions of each analyte. Declustering potential, focusing potential, entrance potential, collision energy, and collision cell exit potential were optimized to obtain the maximum sensitivity with the highest amount of product ions available. Two pairs of Q1/Q3 were chosen for each compound, except for the surrogate, because it was an isotopically labelled compound that is unlikely to be found in environmental samples (BPA: 227.2, 212.2/132.9; Cl-BPA: 261.1, 182.1/210.0; $\mathrm{Cl}_{2}$-BPA: 295.1, 244.1/215.2; $\mathrm{Cl}_{3}$-BPA: 329.1, 250.1/278.0; $\mathrm{Cl}_{4}$-BPA: 365.0, 314.2/ 286.1; BPA-d ${ }_{16}: 241.2,142$ ).

\section{Determination of enzymatic activities}

The samples for the determination of enzymatic activity were collected in sterile plastic containers and immediately transported to the laboratory at $4{ }^{\circ} \mathrm{C}$. The determinations were performed no later than $8 \mathrm{~h}$ after sampling. The activity of six enzymes was determined: alkaline and acid phosphatase (Goel et al. 1998), $\alpha$-glucosidase (Goel et al. 1998), esterase (Boczar et al. 2001), protease (Cadoret et al. 2002) and dehydrogenase (Awong et al. 1985). All enzyme assays were based on colorimetric methods, and are described in literature. Enzymatic activity was expressed as $\mathrm{mM} \mathrm{min}{ }^{-1} \mathrm{~g} \mathrm{MLVSS}^{-1}$.

\section{Determination of physicochemical parameters}

The concentration of mixed liquor suspended solids (MLSS), mixed liquor volatile suspended solids (MLVSS), COD, $\mathrm{BOD}_{5}$, and total nitrogen were determined by standard methods (APHA 2001). Temperature, pH, DO, oxidationreduction potential, and conductivity were determined by specific sensor electrodes (Crison Instruments).

\section{Toxicity tests}

Growth inhibition of activated sludge The information obtained from this test is helpful for choosing suitable BPA spiking concentration, in other words, a concentration that will not cause toxic effects to microorganisms in sludge reducing their ability to degrade the evaluated substances. The growth inhibitory effect of BPA on activated sludge microorganisms was performed in accordance with the ISO 1995 guideline (Strotmann and Pagga 1996). Flasks containing organic test medium and test substance were inoculated with an overnight culture of mixed sewage microorganisms and incubated at $22 \pm 2{ }^{\circ} \mathrm{C}$ for up to $6 \mathrm{~h}$. The test was completed when the exponential growth in the controls ceased. The bacterial biomass was quantified as turbidity in both control and test vessels spectrophotometrically at DO $530 \mathrm{~nm}$. Results were reported as the effect concentration to $50 \%$ inhibition $\left(\mathrm{EC}_{50}\right)$, which were obtained by interpolation from the obtained inhibition curve using ten concentration levels.

\section{Calculations}

Removal efficiency of BPA was calculated by a mass balance in each experiment, using the obtained data of concentrations in water and sorbed on sewage sludge (Stasinakis et al. 2007). After calculating the biodegraded BPA mass, the biotransformation rates were determined, assuming a pseudo-first-order degradation kinetic (Clara et al. 2005). The solid-water distribution coefficients $\left(K_{\mathrm{d}}\right)$ were calculated to analyze the amount of BPA sorbed on sludge in the MBR process during both treatments $(\mathrm{Wu}$ et al. 2011).

\section{Results and discussion}

During the experiments, no BPA concentrations above the LOD of the method were found in influent wastewater, but at the beginning of the experiments, $680 \mu \mathrm{g} \mathrm{kg}^{-1}$ of sorbed BPA was detected in the activated sludge.

Effect of spiked BPA on the growth of microorganisms in the bioreactor

From the inhibition curve, it was determined that BPA caused growth inhibition at very high concentrations $\left(\mathrm{EC}_{50}=29.4 \mathrm{mg} \mathrm{L}^{-1}\right)$. It was observed that concentrations $<1 \mathrm{mg} \mathrm{L}^{-1}$ did not cause any noticeable acute toxic effects on the microorganisms in the bioreactor. The slight acute toxicity of BPA on bacteria is supported by some previously published studies (Groshart and Okkerman 2001; Zhang et al. 2007). Therefore, the working concentrations of BPA had no acute toxic effects and did not interfere with the biological activity in the bioreactor.

\section{Comparison of BPA removal between the two} treatments

The response to the treatments with air and pure oxygen, in relation to the elimination of the spiked BPA in the bioreactor, is shown in Fig. $2 \mathrm{a}$, b. In both treatments, the 

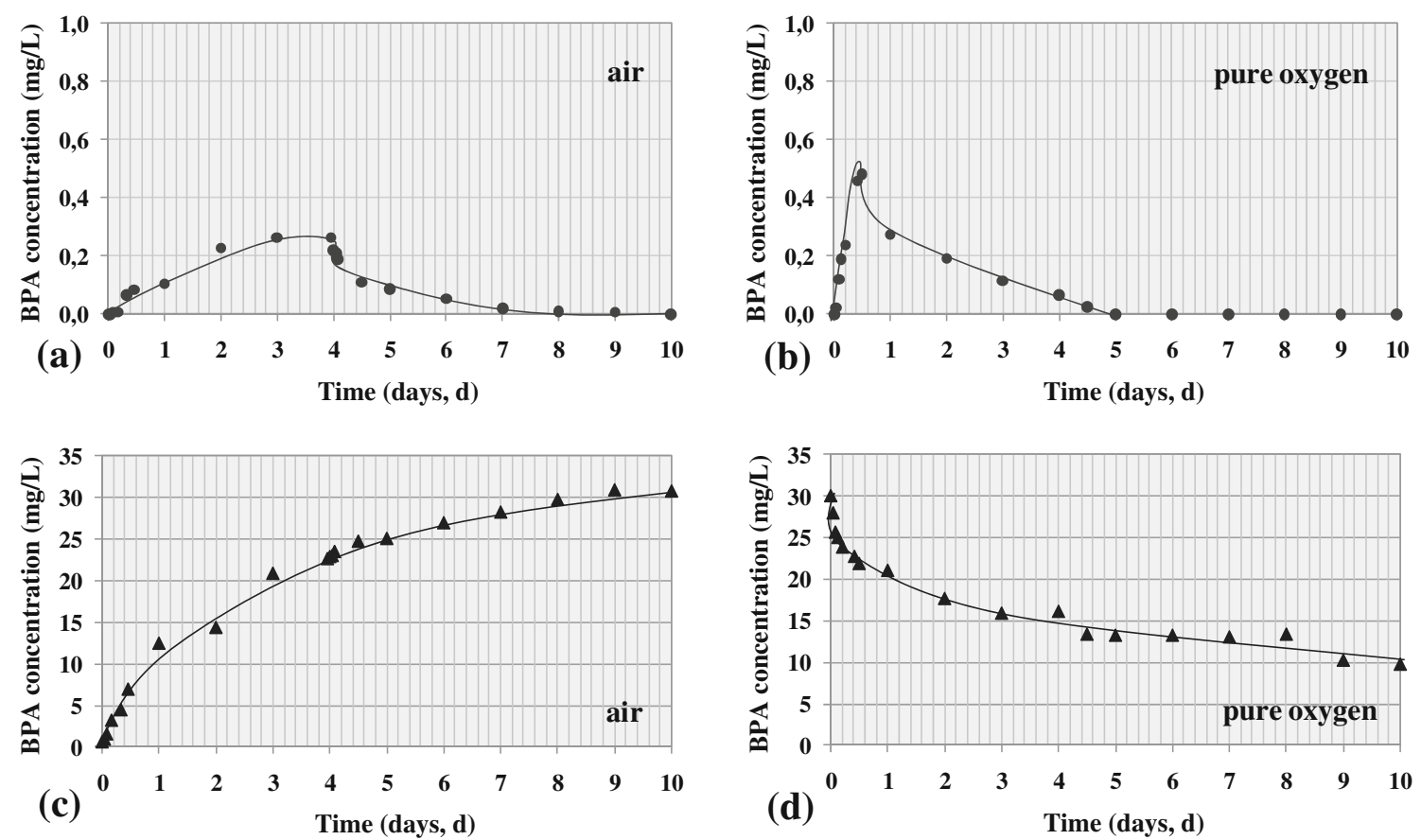

Fig. 2 Measured curves for BPA during each experimentation period with air and pure oxygen. a, b Evolution of effluent BPA concentrations; c, $\mathbf{d}$ evolution of sorbed BPA concentrations to activated sludge in the bioreactor

measured effluent BPA concentrations did not converge eventually towards the spiked influent concentration, as it could be expected. The highest BPA concentrations in the effluent were 0.26 and $0.48 \mathrm{mg} \mathrm{L}^{-1}$ for air and oxygen, respectively. The results constitute evidence that removal processes in the fast dynamic region, like sorption, contribute significantly to the fate of BPA, as Fig. 2 shows. Subsequently, as the experiment progresses, the removal of BPA increased until the measured concentrations in effluent reached the background BPA level, which was below the LOD of the method. In presence of oxygen, BPA concentrations in the effluents reached the background level only after 5 days, which was faster than in the case of the treatment with air, where spiked BPA concentration after 5 days was about $9 \%$ and 10 days were required for reaching the background level.

\section{Distribution of BPA in the MBR system}

Mass balances were performed for both experiments. For the calculations, it was assumed that the main routes for the elimination of BPA from water were only biodegradation and sorption to sludge, since it is known that no other transformation pathways are possible. BPA is a non-volatile compound and tends to sorb to soil. On the other hand, the physical and chemical properties of BPA suggest that hydrolysis is likely to be negligible (UK-BRE 2000). Furthermore, although BPA has the potential to photolyze in water, this is not a probable mechanism in activated sludge systems, where the presence of humic acids compete in absorbing photons protecting BPA from an effective photodegradation, causing a shielding effect (Schmitt-Kopplin et al. 1999). Steady-state conditions were assumed when effluent concentrations stabilized around the background concentrations after each experiment. As a result of mass balances in the bioreactor, it was obtained the whereabouts of BPA treated under MBR conditions. The results are presented in Fig. 3.

\section{Influence of biodegradation and study of enzymatic activities}

It could be concluded that biodegradation was the main elimination pathway for BPA, which is responsible for the return to a new steady-state effluent concentration in both treatments, even though BPA was continuously being spiked into the bioreactor. Biodegradation rate also increases over time with both air and oxygen, and it is logical to assume that the biomass capable of degrading BPA in the system also increases. The simplest explanation is the growth of specific heterotrophic organisms of activated sludge. A large part of BPA was rapidly biodegraded (about $44 \%$ ) during the first day of BPA spiking into the bioreactor, suggesting that the enzymes required for BPA biodegradation were already present. Over the following days of the experiment, biomass acclimatization to BPA 
Fig. 3 Mass flow chart demonstrating the fate of BPA during the two treatments

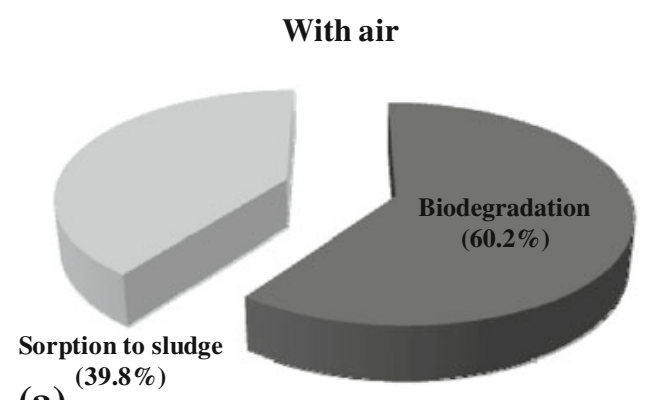

(a)

(b) resulted in a gradual increase of its biodegradation potential. These observations are consistent with the assumption that such degraders are naturally present in the activated sludge, growing under aerobic conditions, since no biological degradation is observed during anoxic or anaerobic conditions (Chen et al. 2008; Schröder 2006; Press-Kristensen et al. 2008). This work has proved that the source of oxygen is of crucial importance in the final fate of BPA. The change from air (traditional source of oxygen) to pure oxygen improved the biodegradation and sorption mechanisms. The use of pure oxygen increased the biodegradation percentages from $60.2 \%$ (air) to $87.4 \%$ after a 10-day period of exposure. The biotransformation rates also confirm this behaviour, since $k_{\text {obs }}$ value was higher for the treatment with oxygen $\left(0.23 \mathrm{~L} \mathrm{~g} \mathrm{X}_{\mathrm{MLVSS}}^{-1} \mathrm{day}^{-1}\right)$ than for the treatment with air $\left(0.15 \mathrm{~L} \mathrm{~g} \mathrm{X}_{\mathrm{MLVsS}}^{-1} \mathrm{day}^{-1}\right)$. Moreover, with pure oxygen the biodegraded mass of BPA per day increased over time since day 2 and more rapidly than in the presence of air, where the biodegradation rates increased significantly from day 4 . Eventually, biodegradation rates reached a background level in both cases. The study of activities showed the changes that bacterial enzymes underwent during both treatments (Fig. 4).

It was observed that the change from air to oxygen had a clear impact on the activity of certain enzymes in activated sludge, since other important parameters that could determine this behaviour, such as MLVSS, $\mathrm{pH}$ and temperature were approximately constant during both treatments. The composition of the inlet (raw wastewater) is a very difficult to control parameter because of its complexity; however, considering the relatively short duration of the experiments and its permanent urban nature, the influence of the inlet was not considered. Acid and alkaline phosphatases, dehydrogenases, and $\alpha$-glucosidases increased rapidly and significantly their activity as a result of the change to pure oxygen, which could explain the increase in the biodegradative potential of microorganisms in the bioreactor. This study corroborates the importance of the dehydrogenase enzyme as indicator of biological activity, since some studies have proved good correlations between dehydro- genase activity and other indicators of sludge viability like oxygen uptake rate (Awong et al. 1985). For this reason, this enzyme assay is considered an indicator of activity in activated sludge (Awong et al. 1985; Dutton et al. 1983). Moreover, this study provides clear evidence that other enzymes, like acid and alkaline phosphatases and $\alpha$-glucosidase, are also indicators of the bacterial activity into the bioreactor. Dehydrogenase and $\alpha$-glucosidase exhibited an increase in their activity of about $100 \%$ as a result of the change from air to oxygen, whereas acid $(83 \%)$ and alkaline $(61 \%)$ phosphatases also showed significant but lower increases. These enzymes are, therefore, good indicators of microbial metabolic activity of activated sludge. Lastly, protease and esterase did not show significant changes during both treatments. The degradative activity of these enzymes is related to their hydrolytic activity which is mainly associated with the cell or lies within the extracellular polymers (ECP) of the flock. ECP could indeed hold and keep a large pool of extracellular enzymes (Goel et al. 1998), and centralized the biological activity in this place.

\section{Influence of sorption to sludge}

BPA has a relatively high octanol-water partition coefficient $\left(\log K_{\text {ow }}=2.2-3.8\right)$ (Staples et al. 1998), which is characteristic for hydrophobic compounds. This is associated with poor hydrosolubility and high tendency to sorb on organic material of the sludge matrix (Stangroom et al. 2000), and suggests that sorption may be an effective mechanism, in addition to biodegradation, for the elimination of BPA from waters. According to our results, in presence of air (Fig. 2c), sorbed BPA tends to remain accumulated in sludge, making it less available to be degraded and persistent. Usually, sludge undergoes various treatments to reduce the sorbed contaminants such as anaerobic digestion, chemical treatment and composting. However, it is known that these procedures are not effective, and contaminants persist in the environment for long 

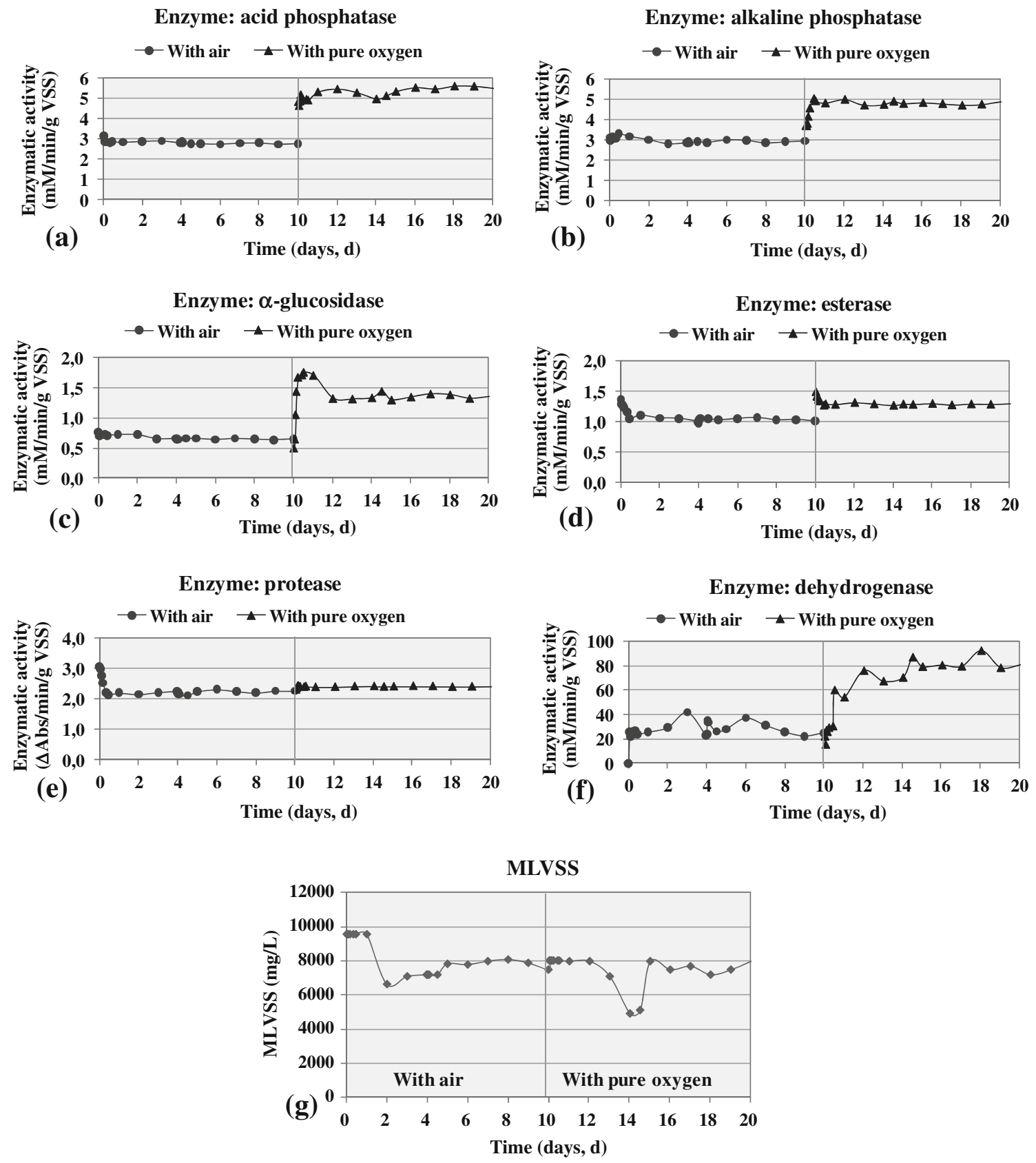

Fig. 4 Evolution curves for enzymatic activities (a-f) during the experimentation period for both treatments (with air and pure oxygen). g Evolution curve for MLVSS during the experimentation time

periods of time. It was observed that oxygen stimulated not only biodegradation, but also favoured BPA desorption from sewage sludge (Fig. 2d). During the treatment with air, $30 \mathrm{mg} \mathrm{kg}^{-1}$ of BPA was sorbed to sludge, which began to be gradually desorbed $3 \mathrm{~h}$ after the beginning of treatment with oxygen. Desorbed BPA was transferred to water, which could explain the increase in BPA concentration in the effluents at the beginning of the treatment with oxygen. It was calculated that $67.4 \%$ of the BPA bound to sludge underwent desorption, which was almost entirely biodegraded once it passed to water system. The differences in the sorption capacity of BPA to sludge were also demonstrated by the calculation of the solid-water distribution coefficients $\left(K_{\mathrm{d}}\right)$ for both treatments $\left(4,574 \mathrm{~L} \mathrm{~kg}^{-S_{S}}{ }^{-1}\right.$ and $508 \mathrm{~L} \mathrm{~kg} \mathrm{SS}^{-1}$ for air and pure oxygen, respectively). The $K_{\mathrm{d}}$ value, in the order of thousands, for the treatment with air indicated a high tendency of BPA to partition onto the sludge. This behaviour changed dramatically with the use 
of pure oxygen, which diminished the sorption tendency of BPA to sludge and favoured desorption process.

\section{Effect of application of pure oxygen into the bioreactor}

Based on studies that establish that BPA degradation requires aerobic conditions (Mohapatra et al. 2010), the novelty of our study is the use of pure oxygen instead of air to improve its permanent removal from wastewaters and sludge. A very distinct difference between both treatments is the significant increase in the enzymatic activity responsible for the biodegradation processes in sludge. These activities contribute to rupture and partially solubilise suspended solids, less complex molecules, including many organic contaminants, increase the soluble COD, decrease viscosity and improve the overall biodegradability (Verma et al. 2007). This could explain the positive effect of the application of pure oxygen on BPA biodegradation in the MBR. Nonetheless, further research is needed to achieve a complete understanding of the effect of pure oxygen on biological processes, especially on enzymatic activities. Some of them are significantly influenced by the redox state of the system, whereas others like protease and esterase are not apparently affected, although they play a crucial role in the hydrolysis of relevant macromolecules and many contaminants. Likewise, further research is needed to determine the effect of oxygen on sorption/ desorption equilibrium. Finally, this procedure has demonstrated to be environmentally friendly because it avoids the application of a tertiary oxidative treatment that usually causes secondary pollution (Lenz et al. 2004). Moreover, the economical balance is positive despite the higher cost of pure oxygen because the use of oxygen also reduces sludge production, which means lower operating time and lower electricity consumption.

\section{Conclusion}

The injection of pure oxygen instead of air into the bioreactor of a MBR pilot plant is relevant innovation for wastewater treatment, allowing the permanent elimination of BPA by increasing the microbial activity inside the bioreactor, which results in an increase of the biodegradation rates of BPA. Likewise, application of pure oxygen facilitated desorption of BPA from sludge, which was subsequently biodegraded. Further studies are required to completely understand the mechanisms and processes involved in the positive effects of pure oxygen. It would also be interesting to study this effect on other emerging organic microcontaminants, which are a serious threat to ecosystems. The successful application of this innovation in the MBR technology could guarantee the permanent elimination of these substances, avoiding their return to environment and ensuring the safety of treated water.

Acknowledgments This work was supported by the regional Government of Andalusia (Research Contract No 3017-00 and Project P09-CTS-4470) and by the Spanish Ministry of Education, Culture and Sports (Project No CTQ2011-24210). The authors are grateful to the Spanish Ministry of Foreign Affairs (Agency for International Cooperation) for the fellowship granted to N. Dorival-García and to the company Air Liquide España for its valuable contribution to this study.

\section{References}

APHA (2001) Standard methods for the examination of water and wastewater. In: Clesceri LS, Greenberg AE, Eaton AD (eds) $20^{\text {th }}$ Edn. American Public Health Association, Washington DC

Awong J, Bitton G, Koopman B (1985) ATP, oxygen uptake rate and INT-dehydrogenase activity of actinomycete foams. Water Res 19(7):917-921. doi:10.1016/0043-1354(85)90151-4

Boczar BA, Forney LJ, Begley WM, Larson RJ, Federle TW (2001) Characterization and distribution of esterase activity in activated sludge. Water Res 35(17):4208-4216. doi:10.1016/S0043-1354 (01)00150-6

Bonefeld-Jørgensen EC, Long M, Hofmeister MV, Vinggaard AM (2007) Endocrine-disrupting potential of bisphenol A, bisphenol A dimethacrylate, 4-N-nonylphenol, and 4-N-octylphenol in vitro: new data and a brief review. Environ Health Perspect 115(1):69-76. doi:10.1289/ehp.9368

Cadoret A, Conrad A, Block JC (2002) Availability of low and high molecular weight substrates to extracellular enzymes in whole and dispersed activated sludges. Enzyme Microb Tech 31(1-2):179186. doi:10.1016/S0141-0229(02)00097-2

Chen J, Huang X, Lee D (2008) Bisphenol A removal by a membrane bioreactor. Process Biochem 43:451-456. doi:10.1016/j.procbio. 2008.01.001

Clara M, Kreuzinger N, Strenn B, Gans O, Kroiss H (2005) The solids retention time - a suitable design parameter to evaluate the capacity of wastewater treatment plants to remove micropollutants. Water Res 39(1):97-106. doi:10.1016/j.watres.2004.08. 036

Drewes JE, Hemming J, Ladenburger SJ, Schaauer J, Sonzogni W (2005) An assessment of endocrine disrupting activity changes during wastewater treatment through the use of bioassays and chemical measurements. Water Environ Res 77:12-23. doi: 10.2175/106143005X41573

Dutton RJ, Bitton G, Koopman B (1983) Malachite Green-INT (MINT) method for determining active bacteria in sewage. Appl Environ Microb 46(6):1263-1267. doi:0099-2240/83/12126305\$02.00/0

Environmental Protection Agency (2005) Cross-species mode of action information assessment: a case study of bisphenol A. Government Reports Announcements \& Index, Issue 26, National Center for Environmental Assessment

Furuya M, Adachi K, Kuwahara S, Ogawa K, Tsukamoto Y (2006) Inhibition of male chick phenotypes and spermatogenesis by Bisphenol A. Life Sci 78(15):1767-1776. doi:10.1016/j.lfs.2005. 08.016

Goel R, Mino T, Satoh H, Matsuo T (1998) Enzyme activities under anaerobic and aerobic conditions in activated sludge sequencing batch reactor. Water Res 32(7):2081-2088. doi:10.1016/S00431354(97)00425-9

Groshart CP, Okkerman PC (2001) Chemical study on Bisphenol A. BKH Consulting Engineers, Report: RIKZ/2001.027, pp 1-94 
Hohenblum P, Gans O, Moche W, Scharf S, Lorbeer G (2004) Monitoring of selected estrogenic hormones and industrial chemicals in groundwaters and surface waters in Austria. Sci Total Environ 333:185-193. doi:10.1016/j.scitotenv.2004.05.009

Hu JY, Chen X, Tao G, Kekred K (2007) Fate of endocrine disrupting compounds in membrane bioreactor systems. Environ Sci Technol 41(11):4097-4102. doi:10.1021/es062695v

Ivashechkin P, Corvini PFX, Dohmann M (2004) Behaviour of endocrine disrupting chemicals during the treatment of municipal sewage sludge. Water Sci Technol 50(5):133-140

Kang JH, Kondo F, Katayama Y (2006) Human exposure to bisphenol A-review. Toxicology 226(2-3):79-89. doi:10.1016/j.tox.2006. 06.009

Kuch ML, Ballschmiter K (2001) Determination of endocrine-disrupting phenolic compounds and estrogens in surface and drinking water by HRGC-(NCI)-MS in the pictogram per liter range. Environ Sci Technol 35:3201-3206. doi:10.1021/es010034m

Lagana A, Bacaloni A, Leva ID, Faberi A, Fago G, Marino A (2004) Analytical methodologies for determining the occurrence of endocrine disrupting chemicals in sewage treatment plants and natural waters. Anal Chim Acta 501:79-88. doi:10.1016/j.aca. 2003.09.020

Lenz K, Beck V, Fuerhacker M (2004) Behaviour of bisphenol A (BPA), 4-nonylphenol (4-NP) and oxidative water treatment processes. Water Sci Technol 50(5):141-147

Lindblom E, Press-Kristensen K, Vanrolleghem PA, Mikkelsen PS, Henze M (2009) Dynamic experiments with high bisphenol-A concentrations modelled with an ASM model extended to include a separate XOC degrading microorganism. Water Res 43(13):3169-3176. doi:10.1016/j.watres.2009.04.030

Liu R, Zhou JL, Wilding A (2004) Microwave-assisted extraction followed by gas chromatography-mass spectrometry for the determination of endocrine disrupting chemicals in river sediments. J Chromatogr A 1038(1-2):19-26. doi:10.1016/j.chroma. 2004.03.030

Meeker JD, Sathyanarayana S, Swan SH (2009) Phthalates and other additives in plastics: human exposure and associated health outcomes. Phil Trans R Soc B 364:2097-2113. doi:10.1098/rstb. 2008.0268

Mohapatra DP, Brar SK, Tyagi RD, Surampalli RY (2010) Physicochemical pre-treatment and biotransformation of wastewater and wastewater sludge, fate of bisphenol A. Chemosphere 78(8): 923-941. doi:10.1016/j.chemosphere.2009.12.053

Nascimento Filho I (2003) Identification of some plasticizers compounds in landfill leachate. Chemosphere 50(5):657-663. doi:10.1016/S0045-6535(02)00581-7

Press-Kristensen K, Lindblom E, Schmidt JE, Hense M (2008) Examining the biodegradation of endocrine disrupting bisphenol A and nonylphenol in WWTPs. Water Sci Technol 57(8):12531256. doi:10.2166/wst.2008.229

Rodríguez-Mozaz S, López de Alda M, Barceló D (2004) Monitoring of estrogens, pesticides and bisphenol $\mathrm{A}$ in natural waters and drinking water treatment plants by solid-phase extraction-liquid chromatography mass spectrometry. J Chromatogr A 1045:8592. doi:10.1016/j.chroma.2004.06.040

Schmitt-Kopplin P, Burhenne J, Freitag D, Spiteller M, Kettrup A (1999) Development of capillary electrophoresis methods for the analysis of fluoroquinolones and application to the study of the influence of humic substances on their photodegradation in aqueous phase. J Chromatogr A 837(1-2):253-265. doi:10.1016/ S0021-9673(99)00079-5

Schröder HF (2006) The elimination of the endocrine disrupters 4-nonylphenol and bisphenol A during wastewater treatmentcomparison of conventional and membrane assisted biological wastewater treatment followed by an ozone treatment. Water Pract Technol 1:1-9. doi:10.2166/WPT.2006060
Smith SR (2009) Organic contaminants in sewage sludge (biosolids) and their significance for agricultural recycling. Phil Trans R Soc A 367:4005-4041. doi:10.1098/rsta.2009.0154

Spring AJ, Bagley DM, Andrews RC, Lemanik S, Yang P (2007) Removal of endocrine disrupting compounds using a membrane bioreactor and disinfection. J Environ Eng Sci 6(2):131-137. doi:10.1139/S06-049

Stangroom S, Collins C, Lester J (2000) Abiotic behaviour of organic micropollutants in soils and the aquatic environment. A review: 2 Transformations. Environ Technol 21(8):845-863. doi: $10.1080 / 09593332108618060$

Staples CA, Dom PB, Klecka GM, O'Block ST, Harris LR (1998) A Review of the environmental fate, effects and exposures of bisphenol A. Chemosphere 36(10):2149-2173. doi:10.1016/S00456535(97)10133-3

Stasinakis AS, Petalas AV, Mamais D, Thomaidis NS, Gatidou G, Lekkas TD (2007) Investigation of triclosan fate and toxicity in continuous-flow activated sludge system. Chemosphere 68(2): 75-381. doi:10.1016/j.chemosphere.2007.01.047

Statgraphics CENTURION XVI, vs 16.0.07 (1982-2009), StatPoint Technologies Inc

Stowell CL, Barvian KK, Young PCM, Bigsby RM, Verdugo DE, Bertozzi CR, Widlanski TS (2006) A role for sulfation-desulfation in the uptake of bisphenol A into breast tumor cells. Chem Biol 13(8):891-897. doi:10.1016/j.chembiol.2006.06.016

Strotmann UJ, Pagga U (1996) A growth inhibition test with sewage bacteria. Results of an international ring test 1995. Chemosphere 32(5):921-933. doi:10.1016/0045-6535(95)00357-6

Takayanagi S, Tokunaga T, Liu X, Okada H, Matsushima A, Shimohigashi Y (2006) Endocrine disruptor bisphenol A strongly binds to human estrogen-related receptor gamma (ERRgamma) with high constitutive activity. Toxicol Lett 167(2):95-105. doi: 10.1016/j.toxlet.2006.08.012

Talsness CE, Andrade AJM, Kuriyama SN, Taylor JA, Von Saal FS (2009) Components of plastic: experimental studies in animals and relevance for human health. Philos Trans R Soc B 364:2079-2096. doi:10.1098/rstb.2008.0281

UK-BRE (Building Research Establishment) (2000) Draft Risk Assessment of Bisphenol A of May 2000. Conducted by the UK rapporteur of behalf of the European Union by (BRE), UK

Vandenberg LN, Hauser R, Marcus M, Olea N, Welshons WV (2007) Human exposure to bisphenol A (BPA). A Review. Reprod Toxicol 24(2):139-177. doi:10.1016/j.reprotox.2007.07.010

Verma M, Brar SK, Tyagi RD, Sahai V, Prévost D, Valéro JR, Surampalli RY (2007) Bench-scale fermentation of Trichoderma viride on wastewater sludge: rheology, lytic enzymes and biocontrol activity. Enzyme Microb Tech 41(6-7):764-771. doi: 10.1016/j.enzmictec.2007.06.013

Vethaak AD, Lahr J, Schrap SM, Belfroid AC, Rijs GB, Gerritsen A (2005) An integrated assessment of estrogenic contamination and biological effects in the aquatic environment of the Netherlands. Chemosphere 59:511-524. doi:10.1016/j.chemosphere.2004.12.053

Vílchez JL, del Olmo M, González-Casado A, Navalón A (2005) Patrones químicos monocloro, dicloro y tricloro derivados del bisfenol-A. Spanish Patent No 2190852

Wu C, Xue W, Zhou H, Huang X, Wen X (2011) Removal of endocrine disrupting chemicals in a large scale membrane bioreactor plant combined with anaerobic-anoxic-oxic process for municipal wastewater reclamation. Water Sci Technol 64(7):1511-1518. doi:10.2166/wst.2011.140

Zafra-Gómez A, Ballesteros O, Navalón A, Vílchez JL (2008) Determination of some endocrine disrupter chemicals in urban wastewater samples using LC-MS. Microchem J 88(1):87-94. doi:10.1016/j.microc.2007.10.003 
Zhang C, Zeng G, Yuan L, Yu J, Li J, Huang G, Xi B, Liu H (2007) Aerobic degradation of bisphenol A by achromobacter xylosoxidans strain B-16 isolated from compost leachate of municipal solid waste. Chemosphere 68(1):181-190. doi:10.1016/j.chemosphere.2006.12.012 